\title{
Systemic therapy for neuroendocrine tumours of gastroenteropancreatic origin
}

\author{
Bristi Basu, Bhawna Sirohi and Pippa Corrie \\ Cambridge University Hospitals NHS Foundation Trust, Cambridge CB2 OQQ, UK \\ (Correspondence should be addressed to P Corrie; Email: pippa.corrie @addenbrookes.nhs.uk)
}

\begin{abstract}
Systemic therapy is one of a number of treatment options routinely used in the management of advanced, unresectable neuroendocrine tumours (NETs). In contrast to many of the other NET treatment modalities, there is at least some evidence base to justify its use. Even so, welldesigned clinical trials are limited, since conducting clinical research in this complex group of rare cancers is challenging. The remit of this review article is to summarise the oncology literature and explain the role of systemic therapy in treating NETs of gastroenteropancreatic origin, identifying benefits and limitations. The molecular biology of NETs is now being unravelled, which affords new opportunities for development of mechanism-driven therapies. The rationale for some of the newer systemic targeted therapies that are showing promise in the clinic is discussed.
\end{abstract}

Endocrine-Related Cancer (2010) 17 R75-R90

\section{Introduction}

Malignant neuroendocrine tumours (NETs) are rare, comprising $\sim 2 \%$ of all malignant tumours diagnosed in the western world. They can arise from neuroendocrine cells anywhere in the body and form a spectrum of cancers that vary in their biology, clinical behaviour, response to treatment and ultimate outcome. Oberndofer first described the carcinoid (or 'karzinoide') tumour in 1907, distinguishing them from other cancer types because of their slow growing nature (Obendorfer 1907). However, it emerged that some tumours with similar histological characteristics were less indolent, and these were separated from the rest of the carcinoids, arising in the vicinity of the pancreas and thus falling into the group now identified as pancreatic endocrine tumours (islet cell tumours). Other tumours in this diverse group are NETs of unknown primary, adrenal gland tumours, poorly differentiated anaplastic small cell tumours and NETs that comprise the multiple endocrine neoplasia type I and II syndromes. The purpose of this review is to summarise the role of systemic treatments in the management of NETs occurring in the gastrointestinal tract and pancreas (GEP NETs), which are the most common sites for NETs to occur.

NETs are frequently characterised by their ability to produce peptides that can cause specific hormonal syndromes. The symptoms of carcinoid syndrome occur when the peptide, serotonin, is secreted by the primary tumour, or more usually, from liver metastases and enters the general circulation from the enterohepatic circulation. Classic symptoms include flushing, diarrhoea and bronchospasm. Less frequent but more catastrophic events include right-sided valvular heart defects, or carcinoid crisis, when large volumes of circulating vasoactive peptides generate a host of symptoms ranging from facial swelling, tachycardia and palpitations to life-threatening vasogenic shock. Since Oberndofer's first description, it has become apparent that NETs can produce a wide variety of peptides including serotonin metabolites, prostaglandins and kinins.

Endocrine tumours arising from the pancreas, also known as islet cell tumours, may produce diverse symptoms as a result of the secretion of glucagon, insulin, gastrin, corticosteroids (ACTH) or vasoactive intestinal peptide. Thus, gastrinomas can result in stomach ulcers and pain, with diarrhoea and fat malabsorption. Insulinomas produce fasting hypoglycaemia with neurological symptoms such as ataxia, confusion, weakness headache and visual symptoms. Glucagonomas can cause weight loss as a result of hyperglycaemia, with poorly healing sores and mucosal inflammation. The excess corticosteroids 
produced as a result of ACTH-producing tumours can cause typical Cushingoid facies, including abnormal fat distribution, reduced muscle mass, hypertrichosis, thin skin and increased risk of infection from the immunosuppressive effects of corticosteroids, as well as increased blood pressure and mental disturbances. VIPomas that release vasoactive intestinal peptide can result in flushing as well as numerous gastrointestinal symptoms including nausea and vomiting, diarrhoea, in addition to constitutional symptoms such as lethargy and weakness. In contrast to the specific symptoms generated by secretory (or 'functional') tumours, nonsecretory (or 'non-functional') tumours may produce morbidity from tumour bulk and physical location.

In general, NETs are associated with a relatively inert behaviour compared with other more common epithelial cancers. However, there is a tendency to become more aggressive over time, and most patients will ultimately die of their disease. The majority of NETs (excepting insulinomas which are often benign) are malignant, and frequent sites of metastasis are lymph nodes, and liver, with less common dissemination to bone, lung and brain. The overall prognosis of NET patients differs widely according to extent of disease, histological grade and site of the primary tumour. In patients with localised NETs, the 5-year survival rates after surgery range between 60 and $90 \%$ (Modlin et al. 2003). However, due to the indolent growth patterns of these tumours, most patients present after their disease has begun to spread, largely because of the non-specific nature of their symptoms (Grama et al. 1992, Shebani et al. 1999). In patients with regional lymph node involvement, 5-year survival rates after surgery are between 50 and $75 \%$, while for patients with distant metastases not amenable to surgery, around $25-40 \%$ of patients will still be alive 5 years from diagnosis (Modlin et al. 2003).

Histopathological classification of this complex group of tumours has proven to be extremely difficult. Until recently there was no internationally approved tumour-node-metastasis (TNM) staging system for NETs, and they were staged according to their organ of origin and whether they were functional or not. Traditionally NETs have been classified according to their embryonic origin into foregut (thymus, respiratory tract, oesophageal, stomach, pancreatic, duodenal and ovarian), midgut (jejunal, ileum, appendiceal, caecal, ascending colon and from Meckel's diverticulum) and hindgut (transverse, descending and sigmoid colon) tumours. The World Health Organization (WHO) 2000 classification defined GEP NETs in a prognosis-oriented manner, taking into account not only the size of tumour, its location and presence of metastases, but also the histological grade, presence of vascular or perineural invasion, hormone production and rate of proliferation (Solcia et al. 2000, Heitz et al. 2004). This distinguished NETs as either being well- or poorly differentiated with presence of mitoses and Ki-67 staining assists the pathologist in judging the benign or aggressive nature of the tumour (Solcia et al. 2000, Bajetta et al. 2005, Vilar et al. 2007). When classified according to these characteristics, welldifferentiated tumours are likely to remain indolent for many years, while poorly differentiated tumours behave more like adenocarcinomas, with much shorter life expectancy (Klöppel et al. 2004, Artale et al. 2005, Bajetta et al. 2005, Panzuto et al. 2005). Thus, even in the presence of metastases, patients with welldifferentiated NETs have a good prognosis, with life expectancy measured in years. Other prognostic indicators have been proposed and validated to varying extents. In the largest review of NET patients published to date (35 825 cases), Yao et al. (2008b) performed a multivariate analysis of patients with wellto moderately differentiated NETs for predictors of outcome. Statistically significant predictors were disease stage, primary tumour site, histological grade, sex, race, age and year of diagnosis.

In 2005 and 2006, the European Neuroendocrine Tumour Society (ENETS) proposed TNM systems for NETs of foregut (including pancreatic), midgut and hindgut origins at Consensus Conferences in Rome (Rindi et al. 2006, 2007). These staging systems included a proposal for grading, in which proliferative indices were incorporated (Grade I: $<2$ mitosis per 10 high-power fields (HPF) and/or Ki-67<2\%; Grade II: 2-20 mitosis per $10 \mathrm{HPF}$ and/or Ki-67 index 3-20\%; Grade III: $>21$ mitosis per HPF and/or Ki-67 index $>20 \%$ ). The prognostic relevance of the TNM staging and grading system of foregut tumours was validated in a retrospective analysis of 202 patients from a German referral centre suggesting that the new classification system could allow prognostic stratification of GEP NETs in clinical practice and research (Pape et al. 2008). Further validation of the TNM classification for midgut and hindgut NETs by clinicopathological studies is awaited. Both the WHO and ENETS systems offer considerable value in current clinical practice.

\section{Treatment options for NET patients}

NETs vary not only in their biological and clinical characteristics, but also in their response to therapy. These factors present a huge challenge to determining the optimum treatment strategy for this diverse group of cancers (Kerr 2006). Indisputably, the best chance of 
cure is surgical resection and thereafter, a variety of treatment options may be considered, however, the evidence base for treatment of NETs is remarkably poor. Despite a variety of treatments offered to the NET patients, few have been subjected to welldesigned controlled trials, and therefore the true benefits of treatments in routine use are by no means entirely clear. Conducting clinical trials in the context of a rare cancer is challenging. As already emphasised, the relatively slow growth patterns of NETs raise issues in design and interpretation of the efficacy end points of early and late phase trials. The majority of those trials undertaken to date have evaluated systemic therapy, with only a handful assessing the role of other treatment modalities. Much of the published data on treatment for NETs can be criticised for being either single institution, often retrospective and assessing heterogeneous populations.

Knowledge about the tumour biology of these rare tumours is now expanding, and a host of novel small molecule drugs targeting pathways known to be up-regulated in NETs are increasing the repertoire of systemic therapeutic strategies which could potentially improve outcomes. There is therefore an imperative to ensure proper evaluation of such new treatments. Collaborative national and international research networks partnering academic and commercial enterprise is beginning to provide a platform from which a solid evidence base can be generated to allow more informed treatment decision making in the near future.

\section{Surgery}

Surgery provides the only possibility of cure, and is mostly reserved for fit patients with limited disease burden (primary and regional lymph node spread). As with other gastrointestinal carcinomas, the liver is the most common site of distant spread. However, unlike other gastrointestinal malignancies, surgical intervention is considerably more effective, and removal of both the metastasis and primary tumour is often considered if technically feasible in patients of excellent performance status, either in a synchronous or staged resection. Various groups have reported impressive 5-year survival rates up to $87 \%$ following surgical resection of NET liver metastases (Que et al. 1995, Chamberlain et al. 2000, Nave et al. 2001, Musunuru et al. 2006). Unfortunately recurrence is observed in the majority of patients (Cho et al. 2008). For some patients, subtotal resection of the bulk of tumour may be appropriate for palliation of symptomatic recurrence from local effects or hormone secretion (Sarmiento et al. 2003).
Orthotopic liver transplantation is also considered an option for patients with hepatic metastatic NETs who have symptoms that are difficult to control with other therapies. Use of transplantation is in debate, however, since $62 \%$ disease-free survival at 1 year and $23 \%$ at 5 years following transplantation suggest that the short supply of livers may be more gainfully employed for conditions with better post-transplant outcomes, where 5-year survival rates in excess of 70\% are observed (Neuberger 1999, Ramage et al. 2005).

\section{Loco-regional strategies}

In patients who are not surgical candidates, regional control of liver metastases resulting in reduced tumour burden and hormone secretion has been achieved using ablative techniques such as radiofrequency ablation, laser ablation and cryotherapy. These loco-regional strategies have yet to be subjected to randomised trials, however, there are reports of promising response rates (RRs) in the range of 35-90\% (Bilchik et al. 1997). Unlike normal hepatocytes, NET liver metastases are supplied by arterial rather than portal blood supply. Therefore, hepatic arterial embolisation is a frequently used treatment for liver disease, producing RRs of over 50\% (Gupta et al. 2003). Chemoembolisation, usually using doxorubicin or cisplatin, is increasingly being employed in patients with large volume liver metastases and poorly controlled symptoms (Kress et al. 2003, Ruutiainen et al. 2007). The optimal regimen, however, is not clear and patients undergoing these loco-regional treatments may be at greater risk of perihepatic sepsis or liver abscesses and infarction (Gates et al. 1999).

\section{Targeted radiotherapy}

Patients whose tumour avidly takes up tracer as part of an octreotide scintigram may be considered for peptide receptor radionuclide therapy (PRRT). This targeted treatment modality is intuitively attractive, but resource intensive, so availability is generally confined to specialist centres with an interest in managing NETs. Furthermore, formal studies to evaluate patient benefits are sparse. Thus, key questions including identification of which patients benefit most from PRRT and at what stage in their disease it is best used remain unanswered. The optimal radionuclide is still to be determined, but treatment with ${ }^{90}$ Yttrium octreotide $\left({ }^{90}\right.$ Y-DOTATOC), ${ }^{90}$ Y-lanreotide and $\mathrm{Lu}^{177}$-DOTA octreotate has been used therapeutically and reported to achieve not only tumour stabilisation but also partial 
responses in up to $30 \%$ of GEP NETs (De Jong et al. 1999, Virgolini et al. 2002, Ezziddin et al. 2006, Kwekkeboom et al. 2008). Alternatively, around 20\% of NETs may be identifiable on a metaiodiobenzylguanidine (MIBG) scan. ${ }^{131}$ Iodine-MIBG has been used in NETs with a positive MIBG scan, and 5-year survival of $60 \%$ and symptomatic relief in the majority of patients is described (Kaltsas et al. 2001a, Mukherjee et al. 2001). Even so, more data are required particularly to clarify the cost-effectiveness of this approach.

\section{Targeted systemic therapy}

Targeted therapy - the focus of most modern anticancer drug development programmes, in effect already exists for NETs, by virtue of the fact that over $70 \%$ of NETs express variable levels of somatostatin receptors on their cell surface. Somatostatin receptor expression is less common in insulinomas and in poorly differentiated NETs. Synthetic somatostatin analogues have long existed and can be delivered systemically in the form of short-acting (octreotide) and long-acting (octreotide LAR and lanreotide Autogel) depot injections. The ensuing suppression of the hormonal axis can achieve significant symptomatic benefit in patients with functional tumours. Octreotide administered at doses of $100-600 \mu \mathrm{g}$ daily in $2-4$ divided doses provides symptomatic responses in up to $60 \%$ of patients and biochemical responses in up to $70 \%$ of patients, with dramatic reduction in the excreted urinary serotonin metabolite, 5-hydroxyindole acetic acid (5HIAA), occurring within weeks of commencing treatment (Jacobsen \& Hanssen 1995). Additional symptom palliation can be gained by tailoring use of other pharmacological agents, such as proton pump inhibitors for gastrinomas and diazoxide for insulinomas.

Several groups have reported anti-proliferative actions from somatostatin analogues, possibly by induction of apoptosis (Imam et al. 1997, Ducreux et al. 2000, Aparicio et al. 2001), although significant tumour shrinkage has been reported to occur in $<5 \%$ of cases (Oberg 2001). The question whether somatostatin analogues therefore should be used in an attempt to control tumour growth and dissemination has proved controversial. However, this year the early results of the PROMID trial were released and suggest they may indeed have true antitumour activity (Rinke et al. 2009). This double-blind trial randomised the patients with metastatic well-differentiated midgut NETs to receive either monthly octreotide LAR $(30 \mathrm{mg}$ ) or placebo injections. Although it was planned to enter 162 patients, an interim analysis of the first 85 patients revealed that octreotide LAR significantly lengthened time to tumour progression (the primary end point of the study) compared with those receiving placebo (14.3 vs 6 months). Although there was no survival benefit in the treatment arm, a possible explanation for this was due to the low number of observable deaths. Octreotide LAR was effective in patients with both functional and non-functional NETs (over $60 \%$ of the patients had non-functioning tumours), while those with the lowest liver tumour burden $(<10 \%)$ experienced the greatest benefit. This is the first trial to report a convincing disease stabilisation and will no doubt impact on standard clinical management of well-differentiated NETs in the very near future.

\section{Systemic treatments: guided by tumour characteristics}

Systemic chemotherapy, the bedrock of non-surgical oncology treatment over the last half century, represents a selective rather than specific treatment for NETs. Not all NETs respond equally to chemotherapy, therefore careful selection of patients is imperative so as to maximise the chance of response and avoid unnecessary toxicity. The degree of differentiation can determine both overall prognosis and probability of response to individual cytotoxic regimens, and therefore an accurate histological characterisation using the WHO classification and increasingly the new TNM system, plays a major role in management (Bajetta et al. 2005). The proliferation rate, measured by the Ki-67 index, may be useful to steer medical treatments (Vilar et al. 2007). Highly proliferative (Ki-67>20\%) and poorly differentiated or anaplastic pancreatic tumours are recognised to behave aggressively, with rapid growth rate and early dissemination. However, this subtype of NET may be more sensitive to cytotoxic chemotherapy, which impairs mitosis in a greater proportion of the rapidly dividing cell population.

The foregut tumours (excluding those of thymic and bronchial origin), particularly the pancreatic NETs are most likely to respond to conventional cytotoxic chemotherapy. Midgut tumours appear often to be low proliferating tumours, and cytotoxic chemotherapy has only resulted in responses of short duration in $<10 \%$ of patients. Therefore, in slow growing tumours, there is an interest to evaluate treatment modalities with mechanisms of action other than cell cycle arrest. Immune modulation using interferon- $\alpha$ (IFN $\alpha$ ) administered s.c. at doses ranging 3-9 million units given 3-7 days a week has been shown to produce RRs up to $50 \%$, measured by biochemical criteria, with durable reduction in tumour growth in up to $15 \%$ 
of patients and symptomatic improvement seen in 40-70\% of patients (Oberg et al. 1983). Somatostatin analogues have been used in conjunction with IFN, and long-term survival gains have been suggested (Ducreux et al. 2000, Filosso et al. 2000, Faiss et al. 2003). However, the benefits of IFN have not definitively been shown to outweigh its toxicity so as yet, IFN is not generally adopted as routine treatment for NETs.

So-called 'borderline tumours' with histological evidence of a well-differentiated phenotype but moderately raised $\mathrm{Ki}-67$ of $2-15 \%$ present management dilemmas that may be clarified by future correlative studies assessing proliferation indices with treatment outcomes (Solcia et al. 2000, O'Toole \& Ruszniewski 2006). In the following sections, the evidence base for treating GEP NETs with systemic chemotherapy is summarised, drawing distinction between NETs of the gastrointestinal tract (welldifferentiated foregut, midgut and hindgut carcinoids), the pancreatic endocrine and anaplastic subtypes, since they appear to follow different clinical paths in terms of aggressiveness and response to cytotoxic agents.

\section{Cytotoxic chemotherapy: when to implement it and how to assess it}

In general, NETs do not show a high degree of sensitivity to chemotherapy, and this has been ascribed to low mitotic rates, presence of high levels of the antiapoptotic protein Bcl-2 and increased expression of the multi-drug resistance gene (MDR-1; Oberg 1993, 1998, Faiss et al. 1996, Wang 1999, Kaltsas et al. 2001b). Therefore, objective RRs to chemotherapy are usually $<30 \%$. However, as previously pointed out, there is some benefit from cytotoxic therapy in a selected population of patients with more aggressive pancreatic NETs, where RRs have been reported between 40 and $70 \%$ (Arnold et al. 2005). Systemic chemotherapy is most often employed when the NET patients present or relapse with rapidly progressive disease or the tumour has pathological features of aggressive disease and a high proliferation rate. Since most NET patients do not meet these criteria in the first instance, in order to avoid overtreatment, it is good practice in general to observe newly presenting asymptomatic patients over a 3-6month period during which time the rate of progression can be monitored using radiological and biochemical means (NCCN Clinical Practice Guidelines in Oncology Neuroendocrine Tumours v.2.2009 www.nccn. org). In this way, some patients can be saved from unnecessary intervention, and live alongside stable disease sometimes for years, even in the presence of extensive liver metastases.
Conventionally, response to chemotherapy is defined as a measurable reduction in tumour size, using internationally agreed criteria, such as the response evaluation criteria in solid tumours criteria (Therasse et al. 2000). However, NET patients may derive clinically significant symptom relief and biochemical reduction in hormonal secretion despite never showing objective tumour shrinkage (Hatton \& Reed 1997). Thus, response evaluation in NET studies may be either measurable change in tumour size, biochemical response or both. Whichever outcome measure is utilised, it is important to balance these potential benefits against the side effects associated with cytotoxic agents. Changes in health-related quality of life as a result of treatment need also to be assessed in order to optimise management of this diverse group of patients (Cella 1995, Kaltsas et al. $2001 \mathrm{~b}$ ). The best validated tool for measuring patient quality of life is the European Organisation for Research and Treatment of Cancer (EORTC) QLQ $\mathrm{C}-30$ instrument. This general health questionnaire is the basis upon which NET patient-specific instruments such as EORTC QLQ-GINET21 have been developed (Davies et al. 2006).

\section{Single agent chemotherapy for NETs}

Over half a century ago, the nitrosurea compound, streptozocin (STZ) was reported to offer meaningful clinical benefits to certain pancreatic NET patients, with reported improvements in hypoglycaemic episodes and tumour load (Table 1; Murray-Lyon et al. 1968). Of the older generation of cytotoxic DNA damaging agents, 5 fluorouracil (5FU), dacarbazine (DTIC) and doxorubicin appeared to have modest activity as single agents. Studies with 5FU report objective RRs ranging from 18 to 26\% (Oberg 1993, 1998, 1999, Moertel et al. 1994). DTIC is reported to have activity in both well- and poorly differentiated NETs. The North American Eastern Co-Operative Group (ECOG) phase II study of 42 patients with advanced pancreatic NETs reported a RR of 33\%, but a median survival of around 19 months was disappointing (Ramanathan et al. 2001). A similar trial by the South West Oncology Group reported a less impressive RR of $16 \%$ and highlighted the problem of drug-related toxicity, namely nausea and vomiting (Bukowski et al. 1994). DTIC has also been used as second-line treatment of NETs progressing on combination chemotherapy, but a RR of just $8 \%$ (Sun et al. 2005) suggests use in this setting cannot be justified.

More recently introduced cytotoxic agents have sadly proved little more effective in the treatment of advanced 
Table 1 Summary of selected single-agent chemotherapy trials for advanced and metastatic neuroendocrine tumours

\begin{tabular}{|c|c|c|c|c|c|}
\hline Type of study & Chemotherapy & $N$ & ORR (\%) & $\begin{array}{c}\text { Median } \\
\text { survival (months) }\end{array}$ & References \\
\hline \multicolumn{6}{|l|}{ Gastrointestinal } \\
\hline \multirow[t]{2}{*}{$\mathrm{Ph} I \mathrm{H}$} & Dox & 81 & 21 & 12 & Engstrom et al. (1984) \\
\hline & DTIC & 63 & 16 & 20 & Bukowski et al. (1994) \\
\hline $\mathrm{Ph}$ II/III & DTIC (second-line) & 70 & 8.2 & 11.9 & Sun et al. (2005) \\
\hline $\mathrm{Ph}$ II & Paclitaxel & 24 & 8 & 18 & Ansell et al. (2001) \\
\hline $\mathrm{Ph}$ II & Docetaxel & 21 & 0 & 24 & Kulke et al. (2004b) \\
\hline $\mathrm{Ph}$ II & Gemcitabine & 18 & 0 & 11.5 & Kulke et al. (2004a) \\
\hline $\mathrm{Ph} I \mathrm{I}$ & Topotecan & 22 & 0 & 22 & Ansell et al. (2004) \\
\hline \multicolumn{6}{|l|}{ Pancreatic } \\
\hline Randomised & STZ & 42 & 36 & 16.5 & Moertel et al. (1980) \\
\hline Randomised & Chlorozotocin & 33 & 30 & 18 & Moertel et al. (1992) \\
\hline $\mathrm{Ph}$ II & DTIC & 42 & 33 & 19 & Ramanathan et al. (2001) \\
\hline $\mathrm{Ph}$ II & Temozolomide & 12 & 8 & 7 & Ekeblad et al. (2007) \\
\hline
\end{tabular}

NETs. A phase II trial of the taxane, paclitaxel, reported a RR of $8 \%$ in 24 NET patients, associated with severe myelosuppression despite co-administered granulocyte-colony stimulating factor (Ansell et al. 2001). A similar study of docetaxel in 21 patients yielded no objective radiological responses (Kulke et al. 2004b), although $31 \%$ patients with raised urinary 5 HIAA levels had a biochemical response. Temozolomide, an oral derivative of dacarbazine, achieved only 1 response out of 12 pancreatic NET patients (Ekeblad et al. 2007). Capecitabine (Krzyzanowska et al. 2006), gemcitabine (Kulke et al. 2004a) and topotecan (Ansell et al. 2004) have all been shown to be inactive as monotherapy in these tumours.

While most chemotherapy trials have focused on pancreatic NETs as being the potentially chemosensitive population, a recent phase II study conducted in the UK addressed whether there is a role for single agent fluoropyrimidine chemotherapy (using capecitabine) in non-pancreatic metastatic NETs. Of 19 patients recruited, 2 had a biochemical response, while 11 patients had stable disease. Time to progression was 5.3 months and overall survival was 23.7 months (Talbot \& Medley, personal communication December 2009). Even so, taken together, these data suggest that singleagent chemotherapy for NETs limited benefit (Oberg 1993, 1999). Thus, single-agent cytotoxics are rarely employed in the management of these tumours.

\section{Combination chemotherapy for NETs}

Despite low single-agent activity, combinations of cytotoxic drugs have been shown to be more beneficial to patients, with acceptable tolerance (Table 2). Standard treatment has been largely defined by a series of relatively small randomised trials performed by ECOG in the late twentieth century. The first ECOG study combined STZ and 5FU for the first time. Compared with STZ alone, STZ plus 5FU improved RR from 36 to $63 \%$, with superior duration of response and survival (Moertel et al. 1980).

STZ-based combinations incorporating either 5FU or doxorubicin consistently generate RRs of between 40 and $60 \%$ in patients with advanced pancreatic NETs translating to a median survival of over 2 years (Moertel et al. 1992, Gonzalez et al. 2003). ECOG went on to compare the two regimens, STZ plus doxorubicin (STZ/Dox) and STZ plus 5FU (STZ/5FU). STZ/Dox was associated with a significantly higher RR (69 vs $45 \%$ ), median time to progression (20 vs 6.9 months) and overall survival (2.2 vs 1.4 years; Moertel et al. 1992). However, the doxorubicin arm was associated with considerably more drug-related toxicity, in particular, myelosuppression, emesis, nephrotoxicity and cardiotoxicity. It is worth noting that the RRs in this study are likely to be overoptimistic, since the criteria for response included clinical assessment of hepatomegaly and reduction in tumour markers rather than exclusively radiological objective response. Subsequent reports of outcomes with STZ/Dox report significantly lower RRs of 6-39\% (Cheng \& Saltz 1999, Kouvaraki et al. 2004, McCollum et al. 2004). ECOG later compared STZ/5FU against doxorubicin/5FU and reported that the STZ containing regimen achieved the better survival outcome in a study which included NETs from various sites of the body (Sun et al. 2005).

The original NET chemotherapy regimens designed by Moertel incorporated i.v. 5FU bolus injections and were associated with considerable severe drug-related 
Table 2 Summary of combination chemotherapy trials for advanced and metastatic neuroendocrine tumours

\begin{tabular}{|c|c|c|c|c|c|c|}
\hline Type of study & Regimen & $N$ & ORR (\%) & $\begin{array}{l}\text { Response } \\
\text { duration } \\
\text { (months) }\end{array}$ & $\begin{array}{l}\text { Median } \\
\text { survival } \\
\text { (months) }\end{array}$ & References \\
\hline \multicolumn{7}{|l|}{ Gastrointestinal } \\
\hline $\mathrm{Ph}$ II & $\mathrm{STZ}+5 \mathrm{FU}$ & 42 & 33 & - & - & Moertel \& Hanley (1979) \\
\hline $\mathrm{Ph} I \mathrm{I}$ & $5 \mathrm{FU}+$ cyclophosphamide & 47 & 26 & - & - & Moertel \& Hanley (1979) \\
\hline $\mathrm{Ph}$ II & $\mathrm{STZ}+5 \mathrm{FU}$ & 80 & 22 & 8 & 16 & Engstrom et al. (1984) \\
\hline $\mathrm{Ph}$ II & $\begin{array}{l}\text { STZ + Dox }+5 \mathrm{FU}+ \\
\text { cyclophosphamide }\end{array}$ & 56 & 31 & - & - & Bukowski et al. (1987) \\
\hline $\mathrm{Ph}$ II & $\begin{array}{l}\mathrm{STZ}+5 \mathrm{FU}+ \\
\text { cyclophosphamide }\end{array}$ & 9 & 22 & - & 10.8 & Bukowski et al. (1987) \\
\hline $\mathrm{Ph}$ II & $\mathrm{STZ}+5 \mathrm{FU}$ & 27 & 16 & 5.3 & 24.3 & Sun et al. (2005) \\
\hline $\mathrm{Ph}$ II & Dox+5FU & 25 & 16 & 4.5 & 15.7 & Sun et al. (2005) \\
\hline \multicolumn{7}{|l|}{ Pancreatic } \\
\hline Randomised & $\mathrm{STZ}+5 \mathrm{FU}$ & 42 & 63 & 17 & 26 & Moertel et al. (1980) \\
\hline $\mathrm{Ph}$ II & Dox $+5 F U+$ cisplatin & 15 & 14 & & 27 & Rougier et al. (1991) \\
\hline $\mathrm{Ph}$ II & Chlorozotocin + 5FU & 44 & 36 & & 11 & Bukowski et al. (1992) \\
\hline Randomised & STZ+Dox & 36 & 69 & 18 & 26 & Moertel et al. (1992) \\
\hline Randomised & $\mathrm{STZ}+5 \mathrm{FU}$ & 33 & 45 & 14 & 18 & Moertel et al. (1992) \\
\hline Retrospective & STZ+Dox & 16 & 6 & 18 & - & Cheng \& Saltz (1999) \\
\hline Retrospective & STZ+Dox & 16 & 6 & 3.9 & 20.2 & McCollum et al. (2004) \\
\hline Retrospective & $\mathrm{STZ}+\mathrm{Dox}+5 \mathrm{FU}$ & 84 & 39 & 9.3 & - & Kouvaraki et al. (2004) \\
\hline $\mathrm{Ph}$ II & $\mathrm{STZ}+\mathrm{Dox}+5 \mathrm{FU}$ & 11 & 55 & 15 & 21 & Rivera \& Ajani (1998) \\
\hline $\mathrm{Ph} \mathrm{I/II}$ & $\begin{array}{l}\text { 5FU + dacarbazine }+ \\
\text { epirubicin }\end{array}$ & 15 & 27 & 10 & & Bajetta et al. (1998) \\
\hline Ph II & Tem + thalidomide & $29(11)$ & $25(45)$ & & NR & Kulke et al. (2006a) \\
\hline $\mathrm{Ph}$ II & Tem + Cap & 17 & 71 & & & Strosberg et al. (2008) \\
\hline $\mathrm{Ph}$ II & Cisplatin + etoposide & 11 & 45 & & & Fjallskog et al. (2001) \\
\hline \multicolumn{7}{|l|}{ Anaplastic } \\
\hline $\mathrm{Ph} I I$ & Cisplatin + etoposide & 18 & 67 & 8 & 16 & Moertel et al. (1991) \\
\hline Retrospective & Cisplatin + etoposide & 41 & 42 & 9.2 & 15 & Mitry et al. (1999) \\
\hline $\mathrm{Ph}$ II & Cisplatin + etoposide & 4 & 67 & & & Fjallskog et al. (2001) \\
\hline $\mathrm{Ph}$ II & $\begin{array}{l}\text { Carboplatin }+ \text { paclitaxel }+ \\
\text { etoposide }\end{array}$ & 78 & 53 & - & 14.5 & Hainsworth et al. (2006) \\
\hline
\end{tabular}

toxicity, in particular, myelosuppression. From studies primarily in colorectal cancer, 5FU administered as a continuous infusion is better tolerated and achieves higher RRs compared with bolus administration (Van Cutsem et al. 2001). A retrospective review of 15 patients treated with STZ combined with infusional 5FU (Gonzalez et al. 2003) suggested equivalence in terms of response (53\% objective response), but improved patient tolerance compared with the standard bolus 5FU-containing regimens described by Moertel et al. (1980, 1992). A more intensive regimen combining 5FU, STZ and cisplatin was developed at the Royal Free Hospital, London, and their review of 35 patients with pancreatic NETs treated with this regimen reported acceptable toxicity and a RR of $34 \%$ (Sarkar et al. 2004).

Other combination chemotherapy regimens have been shown to achieve equivalent or better RRs in phase II studies. Capecitabine combined with oxaliplatin achieved a $30 \%$ objective RR, $20 \%$ biochemical RR and $50 \%$ symptomatic RR in 27 patients with well-differentiated NETs (Bajetta et al. 2007). Temozolomide combined with the antiangiogenic and immunomodulatory agent, thalidomide, has achieved RR of 45\% (Kulke et al. 2006a). Temozolomide has been reported to show in vitro synergy with capecitabine resulting in increased apoptosis of neuroendocrine cell lines, and this combination has raised interest from recent reports that an impressive RR of $71 \%$ has been observed in pancreatic NETs (Fine et al. 2005, Strosberg et al. 2008).

Chemotherapy regimens incorporating triplet chemotherapy combinations such as DTIC, 5FU plus epirubicin, or carboplatin, gemcitabine plus irinotecan have so far not yielded significantly better results, but have been associated with unacceptable side effects (Di Bartolomeo et al. 1995, Bajetta et al. 1998, Ollivier et al. 1998, de Lima Lopes et al. 2007). 
Combining chemotherapy with IFN has been tried, but has not yielded any major benefits (Oberg et al. 1994). Given the paucity of randomised trial data other than the ECOG trials described here, STZ/5FU and STZ/Dox remain the gold standard chemotherapy regimens for unresectable pancreatics NETs in most institutions today.

\section{Cytotoxic treatment for anaplastic NETs}

Cisplatin plus etoposide, a regimen commonly used for small cell lung cancer, is widely utilised for patients with poorly differentiated NETs, based upon Moertel's study of 18 patients which reported a RR of $67 \%$ (Moertel et al. 1991). There was far less activity in well-differentiated tumours, yielding RRs of $14 \%$ in pancreatic NETs and $0 \%$ in metastatic midgut carcinoids (Moertel et al. 1991). A subsequent trial of 36 poorly differentiated NET patients reported a considerably lower RR of $36 \%$, with median survival 19 months (Fjallskog et al. 2001). Toxicity associated with the cisplatin-based regimen was significant, with nephrotoxicity being dose limiting. Therefore, today, in most cases, the second-generation platinum drug, carboplatin is substituted.

Newer chemotherapy combinations tested in this group include irinotecan plus cisplatin (Kulke et al. $2006 \mathrm{~b}$ ) and paclitaxel, carboplatin plus etoposide (Hainsworth et al. 2006). Indirect comparisons suggest that neither regimen is superior to standard platinum/ etoposide regimens, but toxicity is problematic. The overall prognosis remains poor in this group of patients, with a 2-year survival between 20 and 33\%, so there is a pressing need for identification of new therapeutic strategies.

\section{Current chemotherapy trials}

As a result of the drive internationally to improve efficacy of treatment regimens for NETs, a number of trials are investigating early activity of cytotoxic therapy in combination with other chemotherapy or with molecularly targeted agents, and these are listed in Table 3. UKINETS (formerly UK NETwork) is now an established UK society and charity and brings together specialists from all disciplines interested in research into and treatment of NETs. In 2003, it was clear that non-surgical treatment for NETs in the UK was erratic, not least because of the limited and precarious evidence base provided to clinicians upon which to base their treatment decisions. Therefore, UKINETS sets up a first UK NET trial (NET01) with the aims to 1) modernise traditional NET chemotherapy regimens,
2) identify optimal therapy and improve patient outcomes, 3) unite clinicians and systematise patient management across the UK, and 4) undertake translational research studies of pathological and molecular markers that may predict for behaviour and response to chemotherapy.

The NET01 trial is an NCRN-approved randomised phase II study comparing two chemotherapy regimens, Capecitabine/STZ and Capecitabine/STZ/Cisplatin in unresectable metastatic NETs of the foregut and pancreas, including tumours of unknown primary site. In both arms, traditionally used i.v. 5FU is substituted with the oral 5FU prodrug, capecitabine, which has been shown to be equivalent in terms of efficacy but with improved tolerability compared with its predecessor. This study should complete recruitment by the end of 2009, and the results will be used as a basis to design future UK trials of systemic therapy for NETs.

\section{Novel molecular targeted therapy}

As the benefits of systemic chemotherapy have been less than conclusive across the population of NET patients, there is a strong drive to identify the specific molecular aberrations that predispose to the pathogenicity of NETs, so that they may be targeted more effectively. A detailed overview of these mechanismdriven treatments is beyond the scope of this review, however, it has been established that GEP NETs show increased expression of numerous growth factors and their receptors. Growth factors that have been implicated include vascular endothelial growth factor (VEGF), platelet-derived growth factor (PDGF), basic fibroblast growth factor (bFGF), transforming growth factors $\alpha$ and $\beta$ and insulin-like growth factor 1 (IGF1). Of the growth factor receptors that show increased expression, namely epidermal growth factor receptor (EGFR), PDGF receptor, IGF1 receptor and stem cell factor receptor (KIT), a number of receptors possess tyrosine kinase (TK) activity. Two key treatment strategies have been successfully implemented to date. Firstly, monoclonal antibodies (mAbs) targeting a specific ligand or receptor provide specificity against the target and are usually administered as an infusion, intermittently, every few weeks. Secondly, small molecule TK inhibitors (TKIs) are selective rather than specific to one or more TKs and can be taken orally on a daily basis (Fig. 1).

Targeting angiogenesis appears to be an extremely successful strategy for treating a variety of cancers and a number of new anti-angiogenic agents have recently been licensed. Pancreatic NETs and carcinoids 


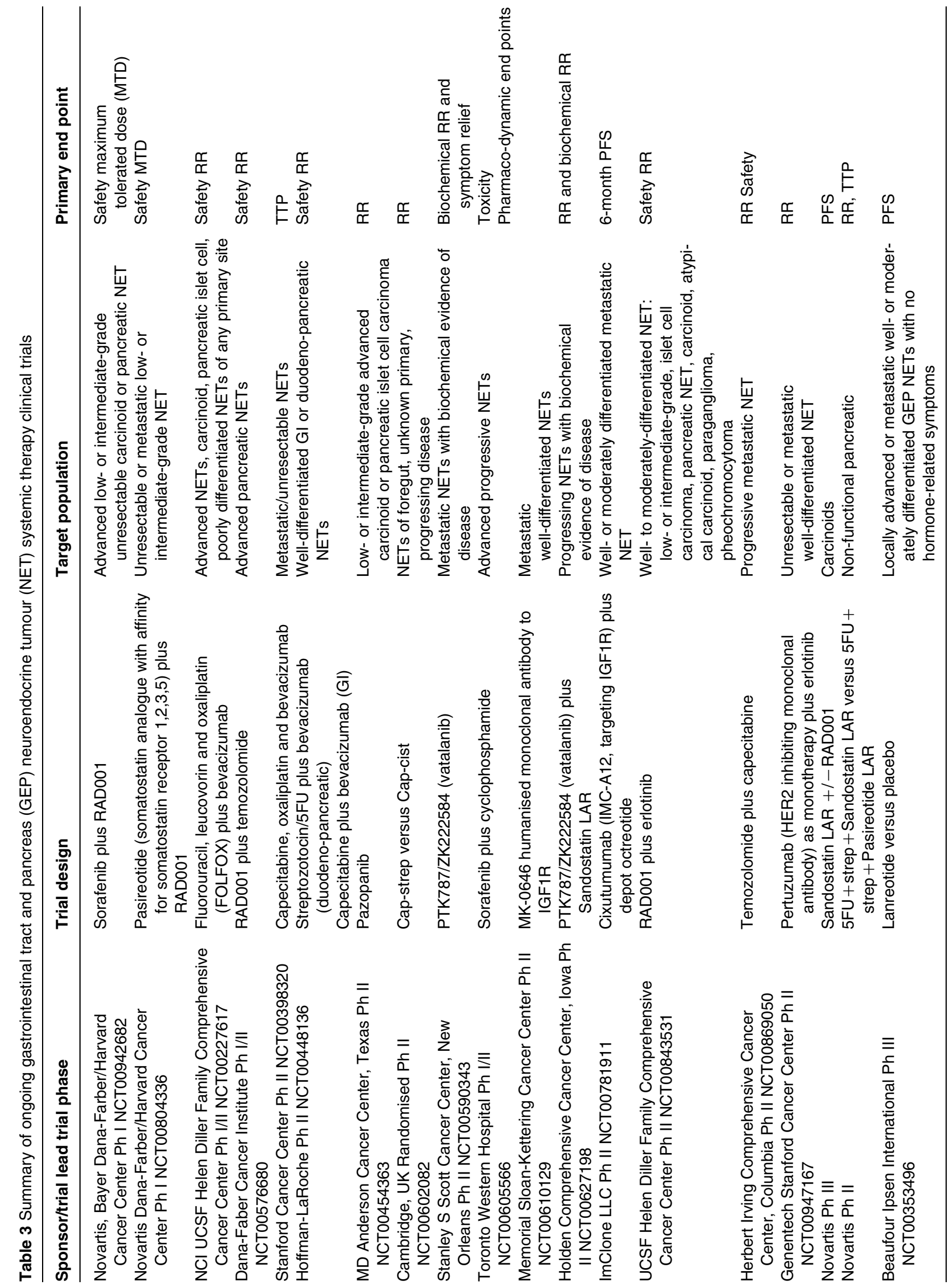




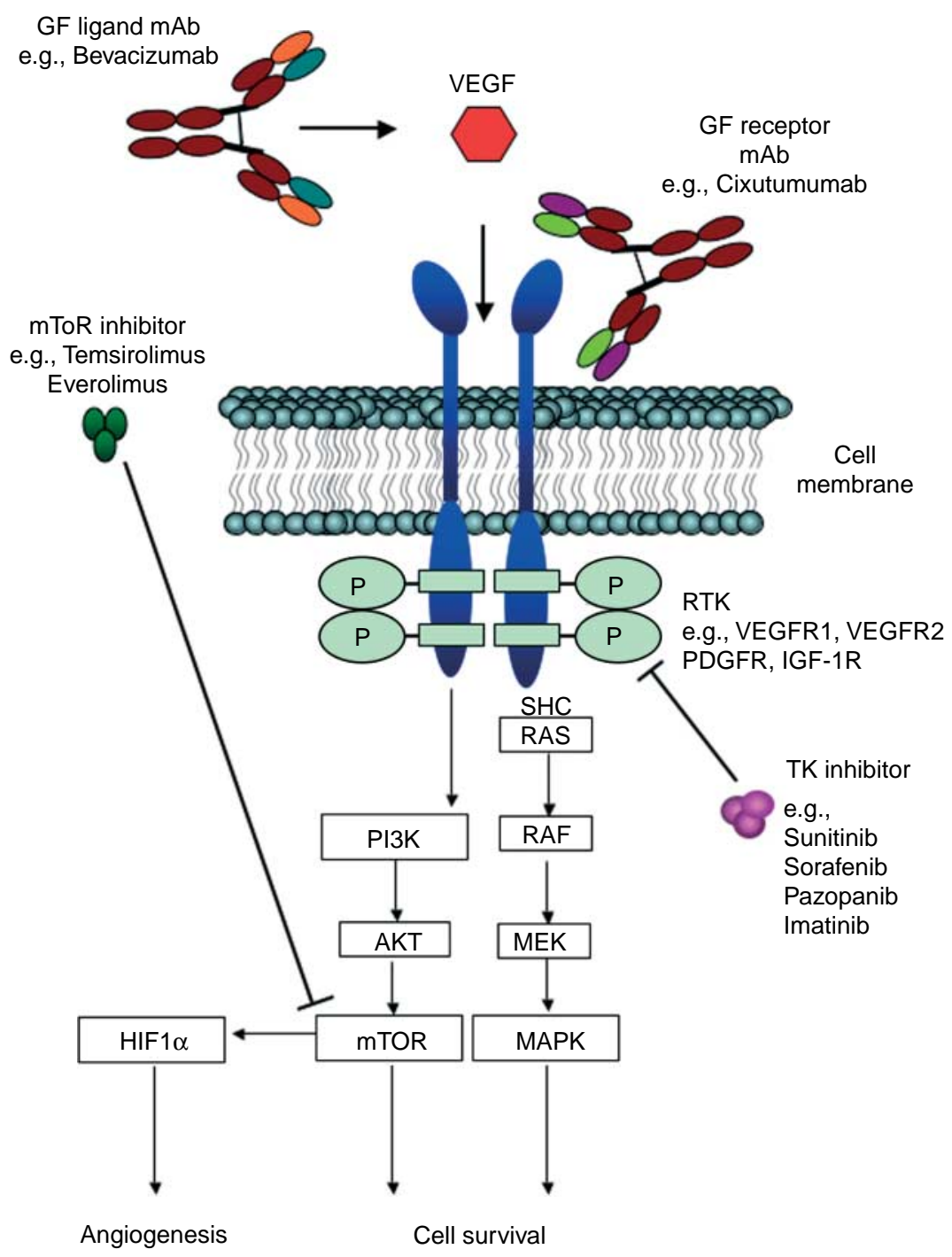

Figure 1 Molecular targeted therapy for NETs.

overexpress both VEGF and the VEGF receptor (VEGFR) subtypes 1 and 2 (Christofori et al. 1995, Terris et al. 1998, La Rosa et al. 2003). A phase II trial randomised 44 patients with advanced carcinoid to receive octreotide combined with pegylated IFNa- $2 b$, or bevacizumab, which is a humanised $\operatorname{IgG} \mathrm{mAb}$ that is directed against VEGF (Yao et al. 2008c). After 18 weeks, $95 \%$ patients receiving bevacizumab remained progression-free, compared with $68 \%$ of those in the IFN $\alpha$ arm. Trials are ongoing, combining bevacizumab with different chemotherapy combinations: 5FU plus oxaliplatin, capecitabine plus oxaliplatin or 5FU plus STZ in various NET patient groups (see Table 3). A new mAb, cixutumumab (IMC-A12), directed against the human type I IGF receptor (IGF1R), is now being studied in NET patients, as a significant proportion of NETs express IGF and it has been reported that high levels of IGF1R expression is associated with rapid tumour growth, increased aggressiveness and lower likelihood of cure in gastrinoma (Furukawa et al. 2005).

Sorafenib, originally developed as a BRAF kinase inhibitor, is known to inhibit kinase activity associated with VEGFR 2, FLT3, PDGFR and FGF receptor-1 (FGFR1). Inhibition of multiple signalling pathways might be expected to be advantageous to achieving effective antitumour activity. However, early data from a phase II trial evaluating sorafenib in 93 NET patients (51 carcinoid and 42 pancreatic islet cell) reported objective RRs in only $7 \%$ of carcinoids and $11 \%$ of pancreatic NETs (Hobday et al. 2007). This agent is currently being tested in combination with other agents 
such as everolimus and chemotherapy (see Table 3) in early phase trials, an attempt to improve efficacy.

Another multi-targeted TKI, sunitinib, with activity against VEGFR 1, 2, and 3, PDGFR $\alpha$ and $\beta$, KIT and RET, has shown impressive efficacy in advanced renal cell cancer, and it now plays a well-established role in the management of this chemoresistant tumour (Motzer et al. 2007). Rather disappointingly, sunitinib produced only low RRs (17\% of pancreatic NET patients and $2 \%$ of carcinoid tumours) in a phase II study of 109 patients with advanced NETs (Kulke et al. 2008). Interestingly, however, the median time to tumour progression was 10.2 and 7.7 months for patients with carcinoid and pancreatic endocrine tumours respectively, suggesting a clinical benefit in terms of disease stabilisation. The clinical efficacy of sunitinib for these tumours was substantiated in a recently reported phase III randomised double blind trial that compared sunitinib against placebo in patients with progressive, well-differentiated malignant pancreatic islet cell tumours (Raymond et al. 2009). Sunitinib resulted in a substantial improvement in median progression free survival (PFS) of $11.1 \mathrm{vs} 5.5$ months, with a hazard ratio of 0.4 in favour of sunitinib.

These data reflect the fact that TKIs may exert cytostatic effect as opposed to cytotoxic effects on tumours and emphasise the need to review the choice of end points for evaluating these agents in clinical trials. The concept of 'disease control' is becoming more widely accepted, whereby stable disease (as opposed to tumour shrinkage) is considered to be a positive response to treatment. Imatinib, another small molecule inhibitor of several TKs, including Bcr-Abl, PDGFR $\alpha$ and $\beta$ and KIT, showed encouraging preclinical data inhibiting NET activity in vitro, and it has now been studied in a phase II trial of 27 advanced NET patients, where despite only 1 partial response being reported, 17 cases showed disease stabilisation (Lankat-Buttgereit et al. 2005, Yao 2007). The anti-angiogenic TKI, pazopanib, which inhibits VEGFR 1, 2 and 3, c-kit and PDGFR, is currently being evaluated in a phase II study in patients with lowor intermediate-grade advanced NETs, underlining the ongoing interest in studying efficacy of TKIs in this disease.

The proto-oncogene Akt is overexpressed in some NETs and its downstream targets include the mammalian target of rapamycin (mTOR). This is a threonine kinase that has been implicated in NET growth via its activity on signalling pathways. In addition, mTORcontaining complexes (mTORCs) are important for hypoxia-inducible factor (HIF) synthesis and therefore mTOR inhibitors could potentially show effects on the key molecules of angiogenic signalling, the HIF proteins. The mTOR inhibitor everolimus (RAD001) has been demonstrated to abrogate NET cell line proliferation and promotes apoptosis in vitro (Zitzmann et al. 2007). Everolimus and another mTOR inhibitor temsirolimus have now been evaluated in phase II studies in NET patients with promising early results (O'Donnell \& Ratain 2007). Everolimus has also been evaluated in combination with depot octreotide in a phase II study (US-52) of 60 NETs patient, with partial responses observed in 5 of $30(17 \%)$ carcinoid patients and 8 of $30(27 \%)$ patients with pancreatic NETs (Yao et al. 2008a). A biochemical RR of $70 \%$ was noted in the 37 patients with elevated chromogranin levels.

The results of the RADIANT-1 phase II study, evaluating everolimus either alone or in combination with Sandostatin LAR in patients with advanced pancreatic NET progressing on chemotherapy, were presented this year at the 11th World Congress on Gastrointestinal Cancer, Barcelona (Yao et al. 2010). This study enrolled patients who were resistant to prior cytotoxic chemotherapy and stratified them into two groups receiving either everolimus monotherapy if they had received prior somatostatin analogues, or combination of everolimus/Sandostatin LAR therapy. The addition of the somatostatin analogue resulted in a higher rate of disease control (tumour shrinkage plus stable disease) $84.4 \%$ compared with $77 \%$, and improved median PFS by 7 months (16.7 vs 9.7 months). Everolimus is now being studied in combination with chemotherapy, for example temozolomide, and with other targeted agents such as sorafenib and the anti-EGFR TKI erlotinib, and data on these novel combinations are eagerly awaited.

\section{Conclusions}

Compared with the common epithelial cancers, NETs are a rare and diverse group of tumours, with varying clinical outcomes and responses to conventional chemotherapy. It appears that well-differentiated gastrointestinal NETs show little evidence of responsiveness to cytotoxic chemotherapy, and therefore it is reasonable to keep this treatment in reserve until the disease alters its clinical course to become more rapidly progressive. Pancreatic NETs, on the other hand, appear to be chemosensitive and systemic cytotoxic chemotherapy can achieve objective tumour responses in up to $60 \%$ of cases. The most commonly used regimens incorporate STZ and 5FU or doxorubicin. Anaplastic NETs show sensitivity to platinum/ 
etoposide regimens, but overall the prognosis from these tumours is poor.

Clearly, there is a great need to improve treatment for inoperable NET patients. Better understanding of the biology of these rare and complex tumours is already beginning to drive development of novel biological therapies which show some early promise. Introduction of targeted systemic therapies, whether alone or concomitantly with cytotoxic agents, should raise the therapeutic index, maximising benefit while minimising chance of harm. It is essential for new treatment strategies to be evaluated in the context of well-designed clinical trials, which can be achieved with the good will of clinicians, scientists and Pharma to generate multinational collaborations focussing on improving outcomes associated with an orphan disease.

\section{Declaration of interest}

The authors declare that there is no conflict of interest that could be perceived as prejudicing the impartiality of the research reported.

\section{Funding}

This research did not receive any specific grant from any funding agency in the public, commercial or not-for-profit sector.

\section{References}

Ansell SM, Pitot HC, Burch PA, Kvols LK, Mahoney MR \& Rubin J 2001 A phase II study of high-dose paclitaxel in patients with advanced neuroendocrine tumours. Cancer 91 1543-1548.

Ansell SM, Mahoney MR, Green EM \& Rubin J 2004 Topotecan in patients with advanced neuroendocrine tumours: a phase II study with significant hematologic toxicity. American Journal of Clinical Oncology 27 232-235.

Aparicio T, Ducreux M, Baudin E, Sabourin JC, De Baere T, Mitry E, Schlumberger M \& Rougier P 2001 Antitumour activity of somatostatin analogues in progressive metastatic neuroendocrine tumours. European Journal of Cancer 37 1014-1019.

Arnold R, Rinke A, Schmidt C \& Hofbauer L 2005 Endocrine tumours of the gastrointestinal tract: chemotherapy. Best Practice \& Research. Clinical Gastroenterology 19 649-656.

Artale S, Giannetta L, Cerea G, Pedrazzoli P, Schiavetto I, Napolitano M, Veronese S, Bramerio E, Gambacorta M, Vanzulli A et al. 2005 Treatment of metastatic neuroendocrine carcinomas based on WHO classification. Anticancer Research 25 4463-4469.
Bajetta E, Rimassa L, Carnaghi C, Seregni E, Ferrari L, Di Bartolomeo M, Regalia E, Cassata A, Procopio G \& Mariani L 1998 5-Fluorouracil, dacarbazine, and epirubicin in the treatment of patients with neuroendocrine tumours. Cancer 83 372-378.

Bajetta E, Catena L, Procopio G, Bichisao E, Ferrari L, Della Torre S, De Dosso S, Iacobelli S, Buzzoni R, Mariani L et al. 2005 Is the new WHO classification of neuroendocrine tumours useful for selecting an appropriate treatment? Annals of Oncology 16 1374-1380.

Bajetta E, Catena L, Procopio G, De Dosso S, Bichisao E, Ferrari L, Martinetti A, Platania M, Verzoni E, Formisano B et al. 2007 Are capecitabine and oxaliplatin (XELOX) suitable treatments for progressing low-grade and high-grade neuroendocrine tumours? Cancer Chemotherapy and Pharmacology 59 637-642.

Di Bartolomeo M, Bajetta E, Bochicchio AM, Carnaghi C, Somma L, Mazzaferro V, Visini M, Gebbia V, Tumolo S \& Ballatore P 1995 A phase II trial of dacarbazine, fluorouracil and epirubicin in patients with neuroendocrine tumours. A study by the Italian Trials in Medical Oncology (I.T.M.O.) Group. Annals of Oncology 6 77-79.

Bilchik AJ, Sarantou T, Foshag LJ, Giuliano AE \& Ramming KP 1997 Cryosurgical palliation of metastatic neuroendocrine tumours resistant to conventional therapy. Surgery 122 1040-1047.

Bukowski RM, Johnson KG, Peterson RF, Stephens RL, Rivkin SE, Neilan B \& Costanzi JH 1987 A phase II trial of combination chemotherapy in patients with metastatic carcinoid tumours. A Southwest Oncology Group Study. Cancer 60 2891-2895.

Bukowski RM, Tangen C, Lee R, Macdonald JS, Einstein AB Jr, Peterson R \& Fleming TR 1992 Phase II trial of chlorozotocin and fluorouracil in islet cell carcinoma: a Southwest Oncology Group Study. Journal of Clinical Oncology 10 1914-1918.

Bukowski RM, Tangen CM, Peterson RF, Taylor SA, Rinehart JJ, Eyre HJ, Rivkin SE, Fleming TR \& Macdonald JS 1994 Phase II trial of dimethyltriazenoimidazole carboxamide in patients with metastatic carcinoid. A Southwest Oncology Group Study. Cancer 73 1505-1508.

Cella DF 1995 Measuring quality of life in palliative care. Seminars in Oncology 22 73-81.

Chamberlain RS, Canes D, Brown KT, Saltz L, Jarnagin W, Fong Y \& Blumgart LH 2000 Hepatic neuroendocrine metastases: does intervention alter outcomes? Journal of the American College of Surgeons 190 432-445.

Cheng PN \& Saltz LB 1999 Failure to confirm major objective antitumour activity for streptozocin and doxorubicin in the treatment of patients with advanced islet cell carcinoma. Cancer 86 944-948.

Cho CS, Labow DM, Tang L, Klimstra DS, Loeffler AG, Leverson GE, Fong Y, Jarnagin WR, D'Angelica MI, Weber SM et al. 2008 Histologic grade is correlated with outcome after resection of hepatic neuroendocrine neoplasms. Cancer 113 126-134. 
Christofori G, Naik P \& Hanahan D 1995 Vascular endothelial growth factor and its receptors, flt-1 and flk-1, are expressed in normal pancreatic islets and throughout islet cell tumourigenesis. Molecular Endocrinology 9 1760-1770.

Davies AH, Larsson G, Ardill J, Friend E, Jones L, Falconi M, Bettini R, Koller M, Sezer O, Fleissner C et al. 2006 Development of a disease-specific quality of life questionnaire module for patients with gastrointestinal neuroendocrine tumours. European Journal of Cancer $\mathbf{4 2}$ 477-484.

Ducreux M, Ruszniewski P, Chayvialle JA, Blumberg J, Cloarec D, Michel H, Raymond JM, Dupas JL, Gouerou H, Jian R et al. 2000 The antitumoural effect of the longacting somatostatin analog lanreotide in neuroendocrine tumours. American Journal of Gastroenterology 95 3276-3281.

Ekeblad S, Sundin A, Janson ET, Welin S, Granberg D, Kindmark H, Dunder K, Kozlovacki G, Orlefors H, Sigurd M et al. 2007 Temozolomide as monotherapy is effective in treatment of advanced malignant neuroendocrine tumours. Clinical Cancer Research 13 2986-2991.

Engstrom PF, Lavin PT, Moertel CG, Folsch E \& Douglass HO Jr 1984 Streptozocin plus fluorouracil versus doxorubicin therapy for metastatic carcinoid tumour. Journal of Clinical Oncology 2 1255-1259.

Ezziddin S, Logvinski T, Yong-Hing C, Ahmadzadehfar H, Fischer HP, Palmedo H, Bucerius J, Reinhardt MJ \& Biersack HJ 2006 Factors predicting tracer uptake in somatostatin receptor and MIBG scintigraphy of metastatic gastroenteropancreatic neuroendocrine tumours. Journal of Nuclear Medicine 47 223-233.

Faiss S, Scherubl H, Riecken EO \& Wiedenmann B 1996 Drug therapy in metastatic neuroendocrine tumours of the gastroenteropancreatic system. Recent Results in Cancer Research 142 193-207.

Faiss S, Pape UF, Bohmig M, Dorffel Y, Mansmann U, Golder W, Riecken EO \& Wiedenmann B 2003

Prospective, randomized, multicenter trial on the antiproliferative effect of lanreotide, interferon alfa, and their combination for therapy of metastatic neuroendocrine gastroenteropancreatic tumours - the International Lanreotide and Interferon Alfa Study Group. Journal of Clinical Oncology 21 2689-2696.

Filosso PL, Croce S, Oliaro A \& Ruffini E 2000 Long-term survival of patients treated with octreotide for metastatic well differentiated neuroendocrine carcinoma of the lung. Journal of Cardiovascular Surgery 41 773-776.

Fine RL, Fogelman DR \& Schreibman S 2005 Effective treatment of neuroendocrine tumours with temozolomide and capecitabine. Journal of Clinical Oncology 23 (Suppl 16S) abstract 4216.

Fjallskog ML, Granberg DP, Welin SL, Eriksson C, Oberg KE, Janson ET \& Eriksson BK 2001 Treatment with cisplatin and etoposide in patients with neuroendocrine tumours. Cancer 92 1101-1107.
Furukawa M, Raffeld M, Mateo C, Sakamato A, Moody T, Ito T, Venzon D, Serrano J \& Jensen R 2005 Increased expression of insulin-like growth factor 1 and/or its receptor in gastrinomas is associated with low curability, increased growth, and development of metastases. Clinical Cancer Research 11 3233-3242.

Gates J, Hartnell GG, Stuart KE \& Clouse ME 1999 Chemoembolization of hepatic neoplasms: safety, complications, and when to worry. Radiographics 19 399-414.

Gonzalez MA, Biswas S, Clifton L \& Corrie PG 2003 Treatment of neuroendocrine tumours with infusional 5-fluorouracil, folinic acid and streptozocin. British Journal of Cancer 89 455-456.

Grama D, Eriksson B, Martensson H, Cedermark B, Ahren B, Kristoffersson A, Rastad J, Oberg K \& Akerstrom G 1992 Clinical characteristics, treatment and survival in patients with pancreatic tumours causing hormonal syndromes. World Journal of Surgery 16 632-639.

Gupta S, Yao JC, Ahrar K, Wallace MJ, Morello FA, Madoff DC, Murthy R, Hicks ME \& Ajani JA 2003 Hepatic artery embolization and chemoembolization for treatment of patients with metastatic carcinoid tumours: the M.D. Anderson experience. Cancer Journal 9 261-267.

Hainsworth JD, Spigel DR, Litchy S \& Greco FA 2006 Phase II trial of paclitaxel, carboplatin, and etoposide in advanced poorly differentiated neuroendocrine carcinoma: a Minnie Pearl Cancer Research Network Study. Journal of Clinical Oncology 24 3548-3554.

Hatton MQ \& Reed NS 1997 Chemotherapy for neuroendocrine tumours: the Beatson Oncology Centre experience. Clinical Oncology 9 385-389.

Heitz PU, Komminoth P, Perren A, Klimstra DS, Dayal Y, Bordi C, Lechago J, Centeno BA \& Klöppel G 2004 Tumours of the endocrine pancreas. In World Health Organization Classification of Tumours, Pathology and Genetics of Tumours of Endocrine Organs, pp 175-208. Eds RA DeLellis, RV Lloyd, PU Heitz \& C Eng. Lyons, France: IARC Press.

Hobday T, Rubin J \& Holen K 2007 MCO44h, a phase II trial of sorafenib in patients with metastatic neuroendocrine tumours (NET): a phase II consortium (P2C) study. Journal of Clinical Oncology 25 (Suppl 18S) abstract 4504.

Imam H, Eriksson B, Lukinius A, Janson ET, Lindgren PG, Wilander E \& Oberg K 1997 Induction of apoptosis in neuroendocrine tumours of the digestive system during treatment with somatostatin analogs. Acta Oncologica 36 607-614.

Jacobsen M \& Hanssen L 1995 Clinical effects of octreotide compared to placebo in patients with gastrointestinal neuroendocrine tumours. Report on a double-blind, randomized trial. Journal of Internal Medicine 237 269-275.

De Jong M, Breeman WA, Bernard HF, Kooij PP, Slooter GD, Van Eijck CH, Kwekkeboom DJ, Valkema R, Macke HR \& Krenning EP 1999 Therapy of neuroendocrine tumours with radiolabeled somatostatin-analogues. Quarterly Journal of Nuclear Medicine 43 356-366. 
Kaltsas G, Korbonits M, Heintz E, Mukherjee JJ, Jenkins PJ, Chew SL, Reznek R, Monson JP, Besser GM, Foley R et al. 2001a Comparison of somatostatin analog and metaiodobenzylguanidine radionuclides in the diagnosis and localization of advanced neuroendocrine tumours. Journal of Clinical Endocrinology and Metabolism 86 895-902.

Kaltsas G, Mukherjee JJ, Plowman PN \& Grossman AB $2001 b$ The role of chemotherapy in the nonsurgical management of malignant neuroendocrine tumours. Clinical Endocrinology 55 575-587.

Kerr C 2006 Oral regimen for metastatic neuroendocrine tumours. Lancet Oncology 7197.

Klöppel G, Perren A \& Heitz PU 2004 The gastroenteropancreatic neuroendocrine cell system and its tumours: the WHO classification. Annals of the New York Academy of Sciences 1014 13-27.

Kouvaraki MA, Ajani JA, Hoff P, Wolff R, Evans DB, Lozano R \& Yao JC 2004 Fluorouracil, doxorubicin, and streptozocin in the treatment of patients with locally advanced and metastatic pancreatic endocrine carcinomas. Journal of Clinical Oncology 22 4762-4771.

Kress O, Wagner HJ, Wied M, Klose KJ, Arnold R \& Alfke H 2003 Transarterial chemoembolization of advanced liver metastases of neuroendocrine tumours - a retrospective single-center analysis. Digestion 68 94-101.

Krzyzanowska MK, Tsao MS, Oza AM, Haider M, Feld R, Knox J, Chin S, Hu H \& Siu LL 2006 Capecitabine plus rofecoxib show no activity in patients with metastatic neuroendocrine tumours. Clinical Oncology 18 88-89.

Kulke MH, Kim H, Clark JW, Enzinger PC, Lynch TJ, Morgan JA, Vincitore M, Michelini A \& Fuchs CS 2004a A phase II trial of gemcitabine for metastatic neuroendocrine tumours. Cancer 101 934-939.

Kulke MH, Kim H, Stuart K, Clark JW, Ryan DP, Vincitore M, Mayer RJ \& Fuchs CS 2004b A phase II study of docetaxel in patients with metastatic carcinoid tumours. Cancer Investigation 22 353-359.

Kulke MH, Stuart K, Enzinger PC, Ryan DP, Clark JW, Muzikansky A, Vincitore M, Michelini A \& Fuchs CS $2006 a$ Phase II study of temozolomide and thalidomide in patients with metastatic neuroendocrine tumours. Journal of Clinical Oncology 24 401-406.

Kulke MH, Wu B, Ryan DP, Enzinger PC, Zhu AX, Clark JW, Earle CC, Michelini A \& Fuchs CS 2006b A phase II trial of irinotecan and cisplatin in patients with metastatic neuroendocrine tumours. Digestive Diseases and Sciences 51 1033-1038.

Kulke MH, Lenz HJ, Meropol NJ, Posey J, Ryan DP, Picus J, Bergsland E, Stuart K, Tye L, Huang X et al. 2008 Activity of sunitinib in patients with advanced neuroendocrine tumours. Journal of Clinical Oncology 26 3403-3410.

Kwekkeboom DJ, de Herder WW, Kam BL, van Eijck CH, van Essen M, Kooij PP, Feelders RA, van Aken MO \& Krenning EP 2008 Treatment with the radiolabeled somatostatin analog [177 Lu-DOTA 0,Tyr3]octreotate: toxicity, efficacy, and survival. Journal of Clinical Oncology 26 2124-2130.

Lankat-Buttgereit B, Horsch D, Barth P, Arnold R, Blocker S \& Goke R 2005 Effects of the tyrosine kinase inhibitor imatinib on neuroendocrine tumour cell growth. Digestion 71 131-140.

de Lima Lopes G Jr, Chiappori A, Simon G, Haura E, Sullivan D, Antonia S, Langevin M, Lush R \& Rocha-Lima CM 2007 Phase I study of carboplatin in combination with gemcitabine and irinotecan in patients with solid tumours: preliminary evidence of activity in small cell and neuroendocrine carcinomas. Cancer 109 1413-1419.

McCollum AD, Kulke MH, Ryan DP, Clark JW, Shulman LN, Mayer RJ, Bartel S \& Fuchs CS 2004 Lack of efficacy of streptozocin and doxorubicin in patients with advanced pancreatic endocrine tumours. American Journal of Clinical Oncology 27 485-488.

Mitry E, Baudin E, Ducreux M, Sabourin JC, Rufie P, Aparicio T, Aparicio T, Lasser P, Elias D, Duvillard P et al. 1999 Treatment of poorly differentiated neuroendocrine tumours with etoposide and cisplatin. British Journal of Cancer 81 1351-1355.

Modlin IM, Lye KD \& Kidd M 2003 A 5-decade analysis of 13,715 carcinoid tumours. Cancer 97 934-959.

Moertel CG \& Hanley JA 1979 Combination chemotherapy trials in metastatic carcinoid tumour and the malignant carcinoid syndrome. Cancer Clinical Trials 2 327-334.

Moertel CG, Hanley JA \& Johnson LA 1980 Streptozocin alone compared with streptozocin plus fluorouracil in the treatment of advanced islet-cell carcinoma. New England Journal of Medicine 303 1189-1194.

Moertel CG, Kvols LK, O’Connell MJ \& Rubin J 1991 Treatment of neuroendocrine carcinomas with combined etoposide and cisplatin. Evidence of major therapeutic activity in the anaplastic variants of these neoplasms. Cancer 68 227-232.

Moertel CG, Lefkopoulo M, Lipsitz S, Hahn RG \& Klaassen D 1992 Streptozocin-doxorubicin, streptozocinfluorouracil or chlorozotocin in the treatment of advanced islet-cell carcinoma. New England Journal of Medicine 326 519-523.

Moertel CG, Johnson CM, McKusick MA, Martin JK Jr, Nagorney DM, Kvols LK, Rubin J \& Kunselman S 1994 The management of patients with advanced carcinoid tumours and islet cell carcinomas. Annals of Internal Medicine 120 302-309.

Motzer RJ, Michaelson MD, Rosenberg J, Bukowski RM, Curti BD, George DJ, Hudes GR, Redman BG, Margolin KA \& Wilding G 2007 Sunitinib efficacy against advanced renal cell carcinoma. Journal of Urology 178 1883-1887.

Mukherjee JJ, Kaltsas GA, Islam N, Plowman PN, Foley R, Hikmat J, Britton KE, Jenkins PJ, Chew SL, Monson JP et al. 2001 Treatment of metastatic carcinoid tumours, 
phaeochromocytoma, paraganglioma and medullary carcinoma of the thyroid with (131)I-meta-iodobenzylguanidine [(131)I-mIBG]. Clinical Endocrinology 55 47-60.

Murray-Lyon IM, Eddleston AL, Williams R, Brown M, Hogbin BM, Bennett A, Edwards JC \& Taylor KW 1968 Treatment of multiple-hormone-producing malignant islet-cell tumour with streptozotocin. Lancet 2 895-898.

Musunuru S, Chen H, Rajpal S, Stephani N, McDermott JC, Holen K, Rikkers LF \& Weber SM 2006 Metastatic neuroendocrine hepatic tumours: resection improves survival. Archives of Surgery 141 1000-1004.

Nave H, Mossinger E, Feist H, Lang H \& Raab H 2001 Surgery as primary treatment in patients with liver metastases from carcinoid tumours: a retrospective, unicentric study over 13 years. Surgery 129 170-175.

Neuberger J 1999 Liver transplantation. Quarterly Journal of Medicine 92 547-550.

Obendorfer S 1907 KarzinoideTumouren des Dunndarms. Frankfurter Zeitschrift für Pathologie 1 425-429.

Oberg K 1993 Chemotherapy and biotherapy in neuroendocrine tumours. Current Opinion in Oncology 5 110-120.

Oberg K 1998 Carcinoid tumours: current concepts in diagnosis and treatment. Oncologist 3 339-345.

Oberg K 1999 Neuroendocrine gastrointestinal tumours - a condensed overview of diagnosis and treatment. Annals of Oncology 10 (Suppl 2) S3-S8.

Oberg K 2001 Chemotherapy and biotherapy in the treatment of neuroendocrine tumours. Annals of Oncology 12 (Suppl 2) S111-S114.

Oberg K, Funa K \& Alm G 1983 Effects of leukocyte interferon on clinical symptoms and hormone levels in patients with mid-gut carcinoid tumours and carcinoid syndrome. New England Journal of Medicine 309 129-133.

Oberg K, Eriksson B \& Janson ET 1994 Interferons alone or in combination with chemotherapy or other biologicals in the treatment of neuroendocrine gut and pancreatic tumours. Digestion 55 (Suppl 3) 64-69.

O'Donnell PH \& Ratain MJ 2007 Evaluating the activity of temsirolimus in neuroendocrine cancer. British Journal of Cancer 177 178-179.

Ollivier S, Fonck M, Becouarn Y \& Brunet R 1998 Dacarbazine, fluorouracil, and leucovorin in patients with advanced neuroendocrine tumours: a phase II trial. American Journal of Clinical Oncology 21 237-240.

O'Toole D \& Ruszniewski P 2006 Medical management of gastroenteropancreatic endocrine tumours: antiproliferative treatment. In Handbook of Neuroendocrine Tumours: Their current and future management, pp 135-156. Eds M Caplin \& L Kvols. Bristol, UK: BioScientifica Ltd.

Panzuto F, Nasoni S, Falconi M, Corleto VD, Capurso G, Cassetta S, Di Fonzo M, Tornatore V, Milione M, Angeletti S et al. 2005 Prognostic factors and survival in endocrine tumour patients: comparison between gastrointestinal and pancreatic localization. Endocrine-Related Cancer 12 1083-1092.
Pape UF, Jann H, Müller-Nordhorn J, Bockelbrink A, Berndt U, Willich SN, Koch M, Röcken C, Rindi G \& Wiedenmann B 2008 Prognostic relevance of a novel TNM classification system for upper gastroenteropancreatic neuroendocrine tumours. Cancer 113 256-265.

Que FG, Nagorney DM, Batts KP, Linz LJ \& Kvols LK 1995 Hepatic resection for metastatic neuroendocrine carcinomas. American Journal of Surgery 169 36-42.

Ramage JK, Davies AH, Ardill J, Bax N, Caplin M, Grossman A, Hawkins R, McNicol AM, Reed N, Sutton R et al. 2005 Guidelines for the management of gastroenteropancreatic neuroendocrine (including carcinoid) tumours. Gut 54 (Suppl 4) iv1-iv16.

Ramanathan RK, Cnaan A, Hahn RG, Carbone PP \& Haller DG 2001 Phase II trial of dacarbazine (DTIC) in advanced pancreatic islet cell carcinoma. Study of the Eastern Cooperative Oncology Group-E6282. Annals of Oncology 12 1139-1143.

Raymond E, Raoul J-L, Niccoli P, Bang Y-J, Borbath I, Lombard-Bohas C, Metrakos P, Lu D-R, Blanckmeister C \& Vinik A 2009 Phase III randomised double-blind trial of sunitinib versus placebo in patients with progressive, well-differentiated malignant pancreatic islet cell tumours. Annals of Oncology 20 (10) (Suppl) abstract O-008.

Rindi G, Kloppel G, Alhman H, Caplin M, Couvelard A, de Herder WW, Eriksson B, Falchetti A, Falconi M, Komminoth P et al. 2006 TNM staging of foregut (neuro)endocrine tumours: a consensus proposal including a grading system. Virchows Archiv 449 395-401.

Rindi G, Kloppel G, Couvelard A, Komminoth P, Korner M, Lopes JM, McNichol AM, Nilsson O, Perren A, Scoazec JY et al. 2007 TNM staging of midgut and hindgut (neuro) endocrine tumours: a consensus proposal including a grading system. Virchows Archiv 451 757-762.

Rinke A, Muller H, Schade-Brittinger C, Klose K, Barth P, Wied M, Mayer C, Aminossadati B, Pape U, Blaker M et al. 2009 Placebo-controlled, double-blind, prospective, randomized study on the effect of octtreotide LAR in the control of tumour growth in patients with metastatic neuroendocrine midgut tumours: a report from the PROMID Study Group. Journal of Clinical Oncology 28 4656-4663.

Rivera E \& Ajani JA 1998 Doxorubicin, streptozocin, and 5-fluorouracil chemotherapy for patients with metastatic islet-cell carcinoma. American Journal of Clinical Oncology 21 36-38.

La Rosa S, Uccella S, Finzi G, Albarello L, Sessa F \& Capella C 2003 Localization of vascular endothelial growth factor and its receptors in digestive endocrine tumours: correlation with microvessel density and clinicopathologic features. Human Pathology 34 18-27.

Rougier P, Oliveira J, Ducreux M, Theodore C, Kac J \& Droz JP 1991 Metastatic carcinoid and islet cell tumours of the pancreas: a phase II trial of the efficacy of combination chemotherapy with 5-fluorouracil, doxorubicin and cisplatin. European Journal of Cancer 27 1380-1382. 
Ruutiainen AT, Soulen MC, Tuite CM, Clark TW, Mondschein JI, Stavropoulos SW \& Trerotola SO 2007 Chemoembolization and bland embolization of neuroendocrine tumour metastases to the liver. Journal of Vascular and Interventional Radiology 18 847-855.

Sarkar D, Williams M, Hochhauser D, Caplin M, Bouvier C, Buscombe J, Tibbals J \& Meyer T 2004 5-Fluorouracil, cisplatin and streptozocin (FCiSt): an effective new regimen for advanced pancreatic neuroendocrine tumours. ASCO Gastrointestinal Cancers Symposium. abstract 100 .

Sarmiento JM, Heywood G, Rubin J, Ilstrup DM, Nagorney DM \& Que FG 2003 Surgical treatment of neuroendocrine metastases to the liver: a plea for resection to increase survival. Journal of the American College of Surgeons 197 29-37.

Shebani KO, Souba WW, Finkelstein DM, Stark PC, Elgadi KM, Tanabe KK \& Ott MJ 1999 Prognosis and survival in patients with gastrointestinal tract carcinoid tumours. Annals of Surgery 229 815-821.

Solcia E, Klöppel G \& Sobin LH 2000 Histological typing of endocrine tumours. In World Health Organisation International Histological Classification of Endocrine Tumours, edn 2, pp 56-58. New York, USA: Springer.

Strosberg JR, Choi J, Gardner N \& Kvols L 2008 First-line treatment of metastatic pancreatic endocrine carcinomas with capecitabine and temozolamide. Journal of Clinical Oncology 26 (Suppl 15S) abstract 4612.

Sun W, Lipsitz S, Catalano P, Mailliard JA \& Haller DG 2005 Phase II/III study of doxorubicin with fluorouracil compared with streptozocin with fluorouracil or dacarbazine in the treatment of advanced carcinoid tumours: Eastern Cooperative Oncology Group Study E1281. Journal of Clinical Oncology 23 4897-4904.

Terris B, Scoazec JY, Rubbia L, Bregeaud L, Pepper MS, Ruszniewski P, Belghiti J, Flejou J \& Degott C 1998 Expression of vascular endothelial growth factor in digestive neuroendocrine tumours. Histopathology $\mathbf{3 2}$ 133-138.

Therasse P, Arbuck SG, Eisenhauer EA, Wanders J, Kaplan RS, Rubinstein L, Verweij J, Van Glabbeke M, van Oosterom AT, Christian MC et al. $2000 \mathrm{New}$ guidelines to evaluate the response to treatment in solid tumours. European Organization for Research and Treatment of Cancer, National Cancer Institute of the United States, National Cancer Institute of Canada. Journal of the National Cancer Institute 92 205-216.

Van Cutsem E, Twelves C, Cassidy J, Allman D, Bajetta E, Boyer M, Bugat R, Findlay M, Frings S, Jahn M et al. 2001 Oral capecitabine compared with intravenous fluorouracil plus leucovorin in patients with metastatic colorectal cancer: results of a large phase III study. Journal of Clinical Oncology 19 4097-4106.

Vilar E, Salazar R, Perez-Garcia J, Cortes J, Oberg K \& Tabernero J 2007 Chemotherapy and role of the proliferation marker $\mathrm{Ki}-67$ in digestive neuroendocrine tumours. Endocrine-Related Cancer 14 221-232.

Virgolini I, Traub T, Novotny C, Leimer M, Fuger B, Li SR, Patri P, Pangerl T, Angelberger P, Raderer M et al. 2002 Experience with indium-111 and yttrium-90-labeled somatostatin analogs. Current Pharmaceutical Design 8 1781-1807.

Wang DG 1999 Apoptosis in neuroendocrine tumours. Clinical Endocrinology 51 1-9.

Yao JC 2007 Neuroendocrine tumours. Molecular targeted therapy for carcinoid and islet-cell carcinoma. Best Practice \& Research. Clinical Endocrinology \& Metabolism 21 163-172.

Yao J, Phan A, Chang D, Wolff R, Hess K, Gupta S, Jacobs C, Mares J, Landgraf A, Rashid A et al. 2008a Efficacy of RAD001 (everolimus) and octreotide LAR in advanced low- to intermediate-grade neuroendocrine tumours: results of a phase II study. Journal of Clinical Oncology 26 4311-4318.

Yao JC, Hassan M, Phan A, Dagohoy C, Leary C, Mares JE, Abdalla EK, Fleming JB, Vauthey JN, Rashid A et al. $2008 b$ One hundred years after "carcinoid": epidemiology of and prognostic factors for neuroendocrine tumours in 35,825 cases in the United States. Journal of Clinical Oncology 26 3063-3072.

Yao JC, Phan A, Hoff PM, Chen HX, Charnsangavej C, Yeung SC, Hess K, Ng C, Abbruzzese JL \& Ajani JA $2008 c$ Targeting vascular endothelial growth factor in advanced carcinoid tumour: a random assignment phase II study of depot octreotide with bevacizumab and pegylated interferon alpha-2b. Journal of Clinical Oncology 26 1316-1323.

Yao JC, Lombard-Bohas C, Baudin E, Kvols LK, Rougier P, Ruszniewski P, Hoosen S, St. Peter J, Haas T, Lebwohl D et al. 2010 Daily oral everolimus activity in patients with metastatic pancreatic neuroendocrine tumours after failure of cytotoxic chemotherapy: a phase II trial. Journal of Clinical Oncology 28 69-76.

Zitzmann K, De Toni EN, Brand S, Goke B, Meinecke J, Spottl G, Meyer HH \& Auernhammer CJ 2007 The novel mTOR inhibitor RAD001 (everolimus) induces antiproliferative effects in human pancreatic neuroendocrine tumour cells. Neuroendocrinology 85 54-60. 